\title{
Crescent Shape Microstrip Antenna for Dual polarized Multi-band Response
}

\author{
Amit A. Deshmukh ${ }^{1}$ (D) and Priyanka Verma ${ }^{2}$ (D) \\ ${ }^{I}$ Professor \& Head, EXTC Department, SVKM's DJSCE, Mumbai, India, \\ email-amitdeshmukh76@rediffmail.com \\ ${ }^{2} P G$ Student, EXTC Department, SVKM's DJSCE, Mumbai, India, email-priyanka6429@gmail.com
}

\begin{abstract}
Novel design of multi-band Crescent shape microstrip antenna is proposed. Modifications in equivalent circular patch yields new resonant modes nearer to the $T M_{11}$ and $T M_{21}$ modes in circular patch that gives four band frequency response showing dual polarizations. Proposed design gives 1 to $1.5 \%$ of bandwidth at each frequency with broadside radiation pattern. The resonance frequency equation by defining the resonant length at each mode in the Crescent shape patch, is proposed. The frequency calculated using the same agrees closely with simulated result. The air suspended design of crescent shape patch is presented which yields co-polar peak gain of above $1.5 \mathrm{dBi}$.
\end{abstract}

Index Terms - Circular microstrip antenna, Crescent shape microstrip antenna, Multi-band microstrip antenna, Dual polarization

\section{INTRODUCTION}

Multi-band antennas are needed in applications where signal trans-reception is carried out at closely spaced frequencies [1]. While using antenna variations like, dipole, helical, loop or horn, multiple antennas are required which caters to each of the frequency bands [1]. This increases the system cost. In this aspect microstrip antenna (MSA) offers design simplicity and flexibility where single radiating element with suitable modifications can cater to multiple frequencies [2], [3]. In MSAs different radiating patch shapes like rectangular/square, circular, equilateral triangular and compact variations like, ring and semi-circular shape, have been used [1]-[3]. Using these radiating shapes, with reference to their fundamental and higher order modes, multi-band response can be realized however pattern characteristics are not identical across each mode. For similar patterns, multi-band MSAs have been realized either by cutting a slot in the patch or by placing stub on patch edges or by using multiple patches in the same configuration which caters to different frequency bands [3]-[10]. The slot cut method is preferred since it does not increase the patch size (as observed in stub loaded MSA) neither it requires active (diode) or passive (capacitor) elements that along with their biasing circuit helps in selecting different frequency bands. The dual or multi-band response is realized with reference to fundamental patch mode and to have same polarization, mode introduced by slot offers similar radiation characteristics to that given by fundamental patch mode [3]-[10]. To realize multiband response stacked configuration using regular patch shapes or fractal patches or genetic algorithm 
optimized patch antenna have been reported [11]-[13]. The dual polarization will be obtained when mode due to slot is orthogonal to patch mode [3], [4], [7]. Multiband and dual-polarized antennas are attractive for mobile communications applications [14]. Along with regular shapes, modified patch shapes like Spanner shape antenna, modified rectangular ring shape antenna loaded with semi-circular patch have been used for achieving wideband or dual band characteristics [15], [16]. However, in [15], [16] detailed study to explain effects of modifications in patch shapes on frequency and impedance, for achieving reported antenna characteristics is not given. Using a Crescent shape patch, ultra-wide band and dual band response is obtained [17]-[19]. However, in the literature explanation for the resonant modes in Crescent shape patch and resonance frequency formulation for the same is not given.

In this paper, novel design of Crescent shape MSA embedded with rectangular slot is presented for multi-band dual polarized response. A glass epoxy substrate $\left(\varepsilon_{\mathrm{r}}=4.3, \mathrm{~h}=0.16 \mathrm{~cm}\right.$, $\left.\tan \delta=0.02\right)$ is selected in the present study. The Crescent shape patch is derived from circular MSA (CMSA) by embedding circular slot on the periphery of CMSA. The excited resonant modes of Crescent shape patch were studied. MSA offers new resonant modes those lies nearer to the fundamental $\mathrm{TM}_{11}$ and second order $\mathrm{TM}_{21}$ modes of equivalent CMSA. The frequency tuning in new modes is obtained by changing the circular slot radius. With reference to the given feed position, modal currents on the patch exhibits integer multiples of half wavelength variations at fundamental and higher order resonant modes. By studying modal current variations, resonant length formulation at fundamental and higher order modes of Crescent shape patch is presented. Frequency calculated using the same agrees closely with simulated results at every mode. With an impedance matching at first three modes, triple band response is obtained in Crescent shape MSA. It gives simulated and measured frequencies of 576, 920 and $1250 \mathrm{MHz}$ with VSWR BW of 1 to 1.5\%. Triple band MSA offers broadside radiation pattern across three frequencies with dual polarization, i.e. E-plane is directed along $\phi=90^{\circ}$ at first and third mode and along $0^{\circ}$, at second mode. Further a design of Crescent shape MSA with rectangular slot is proposed. Slot controls the input impedance at first resonant mode and along with fourth resonant mode, four band frequency response is obtained. At each of the frequency, antenna offers 1 to $1.5 \%$ of VSWR BW. MSA offers broadside pattern with dual polarization at alternate frequencies. Using proposed formulations, procedure to design Crescent shape MSA at given fundamental mode frequency is also presented. To increase the antenna gain, air suspended design of Crescent shape MSA is presented which yields broadside gain of 1.5 to $5 \mathrm{dBi}$ across four frequencies. In the proposed work, although widely reported slot cut techniques are used, but a new configuration of Crescent shape MSA is discussed with relevant resonant mode explanation and their formulation. Similar detailed study for Crescent shape MSA is not reported. Further its variants for multi-band dual polarized response are presented. They offer either triple or four band response with dual polarizations at consecutive modes. Antenna designs proposed were first studied using IE3D software followed by 
measurements using high frequency instruments like, $\mathrm{ZVH}-8, \mathrm{FSC}-6$ and SMB $-100 \mathrm{~A}$.

\section{CRESCENT SHAPE MSA}

A Crescent shape MSA is shown in Fig. 1(a). In equivalent CMSA, patch radius ' $r$ ' is calculated for $\mathrm{TM}_{11}$ mode frequency of $950 \mathrm{MHz}$, and it is found to be $4.5 \mathrm{~cm}$. CMSA when simulated for ' $\mathrm{x}_{\mathrm{f}}$ ' $=2.5$ and ' $\mathrm{y}_{\mathrm{f}}{ }^{\prime}=2.5 \mathrm{~cm}$, yields $\mathrm{f}_{\mathrm{TM} 11}=936 \mathrm{MHz}$ and $\mathrm{f}_{\mathrm{TM} 21}=1564 \mathrm{MHz}$. On the perimeter of this CMSA circular slot of radius ' $r_{s}$ ' is cut, that realizes Crescent shape MSA. To study its resonant mode behaviour, patch is simulated for increasing ' $r_{s}$ ' and its resonance curve plots and surface current distribution at observed resonant modes for ' $r_{s}$ ' $=3.0 \mathrm{~cm}$ is shown in Figs. $1(b) \& 2(a-c)$.

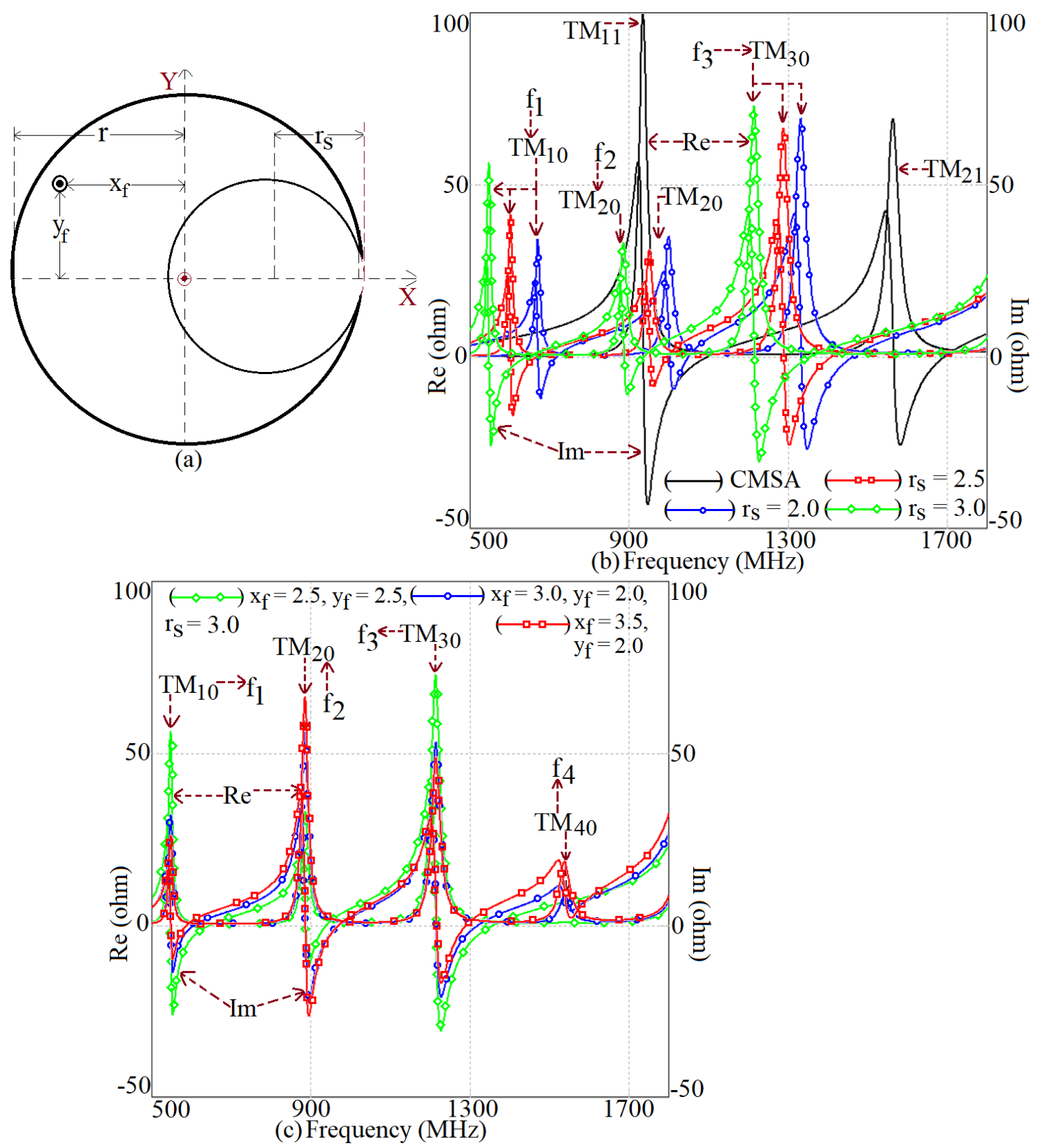

Fig. 1. (a) Crescent shape MSA, its resonance curve plots for variation in (b) slot radius ' $r_{s}$ ' and (c) feed positions ( $\left.x_{f}, y_{f}\right)$

With increase in ' $r_{s}$ ', three resonant modes $\left(f_{1}, f_{2}\right.$ and $\left.f_{3}\right)$ are observed whose frequencies reduce with slot radius. At three resonant modes, currents exhibit integer multiples of half wavelength 
variations along patch perimeter and inside the patch. Hence these modes are referred at as $\mathrm{TM}_{\mathrm{m} 0}$. Here index ' $\mathrm{m}$ ' is for the variation along patch perimeter and it equals $1,2,3 \ldots$ i.e. integer number of half wavelength variations. The '+' and '-' sign in current plots indicate the field polarity.

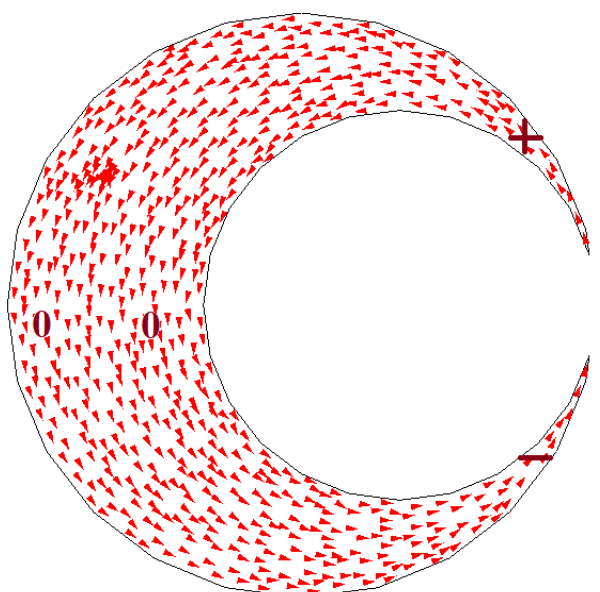

(a) $\mathrm{f}_{10}=549 \mathrm{MHz}$

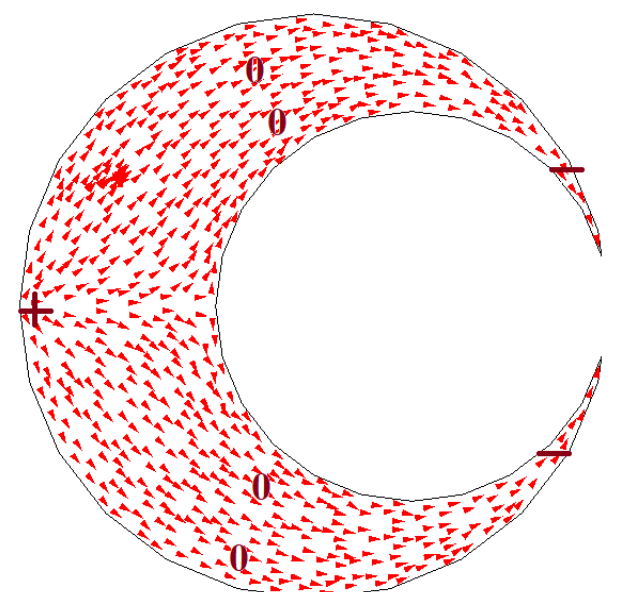

(b) $\mathrm{f}_{20}=888 \mathrm{MHz}$

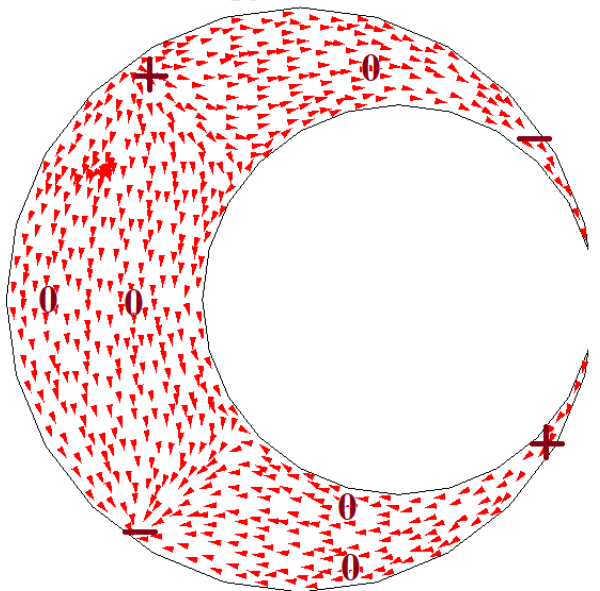

(c) $\mathrm{f}_{30}=1214 \mathrm{MHz}$

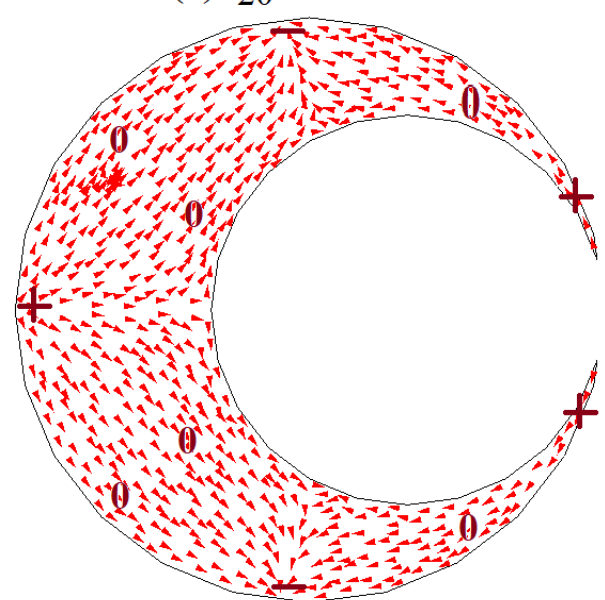

(d) $\mathrm{f}_{40}=1537 \mathrm{MHz}$

Fig. 2 Surface current distributions for observed resonant modes for $r_{s}=3.0$ and $(a-c) x_{f}=2.5, y_{f}=2.5$ and $(d) x_{f}=3.0$, $\mathrm{yf}_{\mathrm{f}}=2.0$

The second index is for the variation along modified patch radius. Here it is taken equal to zero, as resonant mode frequencies for radial field variation will be present at higher frequency values than that of fundamental $\left(\mathrm{TM}_{10}\right)$ and few of the higher order resonant mode $\left(\mathrm{TM}_{20}, \mathrm{TM}_{30}, \ldots\right)$ frequencies. The surface current distribution at second mode $\left(\mathrm{TM}_{20}\right)$ is similar to the modified $\mathrm{TM}_{11}$ mode of equivalent CMSA. At first $\left(\mathrm{TM}_{10}\right)$ mode, maximum of currents is aligned along vertical direction, hence E-plane is directed along $\phi=90^{\circ}$. With reference to directions of current maxima at second $\left(\mathrm{TM}_{20}\right)$ and third $\left(\mathrm{TM}_{30}\right)$ mode, E-plane is directed along $\phi=0^{0}$ and $90^{\circ}$, respectively. Thus, with reference to first three modes, antenna will offer dual polarization. Resonance curve plots for ' $r_{\mathrm{s}}$ ' $=$ $3.0 \mathrm{~cm}$ and for varying feed positions are shown in Fig. 1(c). With increase in x-coordinate of the feed, impedance at $\mathrm{TM}_{10}$ and $\mathrm{TM}_{30}$ modes reduces as feed is placed nearer to its minimum field point. However, impedance at $\mathrm{TM}_{20}$ mode increases. With increase in ' $\mathrm{x}_{\mathrm{f}}$ ' additional resonant mode at frequency of around $1500 \mathrm{MHz}$ is observed. At this mode, since surface currents shows four half 
wavelength variations along patch perimeter, excited mode is referred to as $\mathrm{TM}_{40}$, as shown in Fig. 2(d). This modal distribution is similar to $\mathrm{TM}_{21}$ mode of CMSA.

\section{RESONANT LENGTH FORMULATION FOR CRESCENT SHAPE MSA}

Further by studying surface current distributions at various modes, formulation in resonant length is proposed for the new structure. At $\mathrm{TM}_{10}$ mode, effective patch width as seen by modal currents reduces with slot radius. This reduction in width $\left(\mathrm{w}_{\mathrm{e}}\right)$ will affect the effective dielectric constant $\left(\varepsilon_{\mathrm{re}}\right)$ as seen by currents, as given in (1) and (2). The units for patch dimensions mentioned in equation are in $\mathrm{cm}$. Surface currents at $\mathrm{TM}_{10}$ mode were seen to be circulating around slot perimeter and hence formulation in its resonant length is obtained by using (3). The frequency as calculated using (4), agrees closely with the simulated frequency, obtained using IE3D as shown in Fig. 3(a). Here the frequency as calculated using (4) is in GHz.

$$
\begin{gathered}
\mathrm{w}_{\mathrm{e}}=2\left(\mathrm{r}-\mathrm{r}_{\mathrm{S}}\right) \\
\varepsilon_{\mathrm{re}}=\left(\varepsilon_{\mathrm{r}}+1 / 2\right)+\left(\varepsilon_{\mathrm{r}}-1 / 2\right)\left(1 / \sqrt{1+12 \mathrm{~h} / \mathrm{w}_{\mathrm{e}}}\right)\left(\mathrm{r}-0.65 \mathrm{r}_{\mathrm{s}} / \mathrm{r}\right) \\
\mathrm{l}_{\mathrm{e}}=2 \mathrm{r}_{\mathrm{s}} \pi \\
\mathrm{f}_{\mathrm{r}}=30 / 2 \mathrm{l}_{\mathrm{e}} \sqrt{\varepsilon_{\mathrm{re}}}
\end{gathered}
$$

At $\mathrm{TM}_{20}$ mode, currents show two half wavelength variations along patch perimeter. The effective patch width as seen by modal currents reduces with ' $r_{s}$ '. The modified width and effective dielectric constant are calculated by using (1) and (2). As $\mathrm{TM}_{20}$ mode is similar in distribution to $\mathrm{TM}_{11}$ mode in CMSA, resonance frequency equation for its $\mathrm{TM}_{11}$ mode is used here. The effective patch radius at this mode which includes the effect of slot radius is formulated by using (5). The frequency as calculated using (6) for $\mathrm{k}_{\mathrm{mn}}=1.84118$, in ' $\mathrm{GHz}$ ', matches closely with the simulated frequency as shown in Fig. 3(b).

$$
\begin{aligned}
& \mathrm{r}_{\mathrm{e}}=\mathrm{r}+\left(\mathrm{r}_{\mathrm{s}} / \mathrm{r}\right)\left(\mathrm{r}_{\mathrm{s}} \pi / 2.9\right) \\
& \mathrm{f}_{\mathrm{r}}=30 \mathrm{k} \mathrm{mn} / 2 \mathrm{r}_{\mathrm{e}} \pi \sqrt{\varepsilon_{\mathrm{re}}}
\end{aligned}
$$

At $\mathrm{TM}_{30}$ mode, as currents exhibits three half wavelength variations along outer and inner circular patch perimeter (outer patch circle and inner slot circle) resonant length is calculated by using (7). Here average of these two lengths is considered. However, it was observed that effective resonant length lies more closer to the inner circular slot radius hence factor of 2.4 is considered in (7). The effective dielectric constant is calculated by using (1) and (8). The resonance frequency at $\mathrm{TM}_{30}$ mode is calculated by using (9). The frequency as calculated matches closely with the simulated frequency as shown in Fig. 3(c). 


$$
\begin{gathered}
\mathrm{l}_{\mathrm{e}}=\left(2 \mathrm{r} \pi+2 \mathrm{r}_{\mathrm{s}} \pi\right) / 2.4 \\
\varepsilon_{\mathrm{re}}=\left(\varepsilon_{\mathrm{r}}+1 / 2\right)+\left(\varepsilon_{\mathrm{r}}-1 / 2\right)\left(1 / \sqrt{1+12 \mathrm{~h} / \mathrm{w}_{\mathrm{e}}}\right) \\
\mathrm{f}_{\mathrm{r}}=3 \times 30 / 2 \mathrm{l}_{\mathrm{e}} \sqrt{\varepsilon_{\mathrm{re}}} \\
\text { \%Error }=\left|\mathrm{f}_{\text {ie } 3 \mathrm{~d}}-\mathrm{f}_{\text {calc }} / \mathrm{f}_{\mathrm{ie} 3 \mathrm{~d}}\right| \times 100
\end{gathered}
$$

The surface currents at $\mathrm{TM}_{40}$ mode are similar to the $\mathrm{TM}_{21}$ mode of equivalent CMSA. The effective patch radius here is calculated by modifying it with fractional perimeter length of circular slot as given in (5). As width seen by modal surface currents is reduced with slot radius, effective width for currents and effective dielectric constant are calculated by using (1) and (2). The frequency for $\mathrm{TM}_{40}$ mode is calculated by using (6) for $\mathrm{k}_{\mathrm{mn}}=3.05424$. It agrees closely with simulated result for different slot radius as shown in Fig. 3(d). Thus, above proposed formulation gives resonant length and frequency formulation for new Crescent shape geometry at fundamental and few of the higher order modes which matches within $5 \%$ with the simulations.

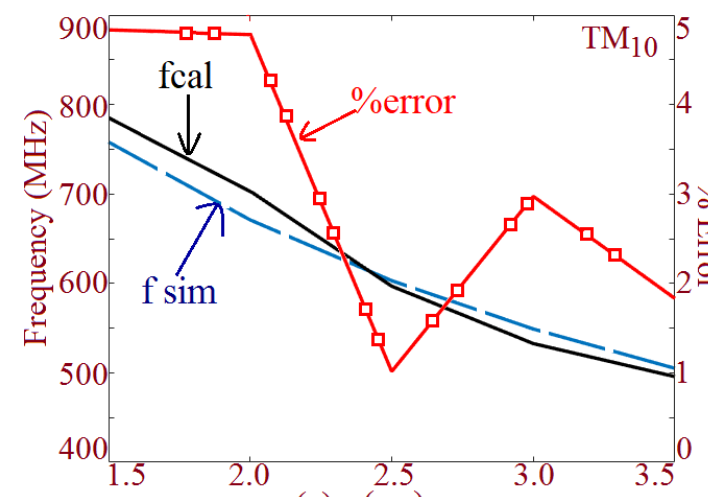

(a) $\mathrm{r}_{\mathrm{S}}(\mathrm{cm})$

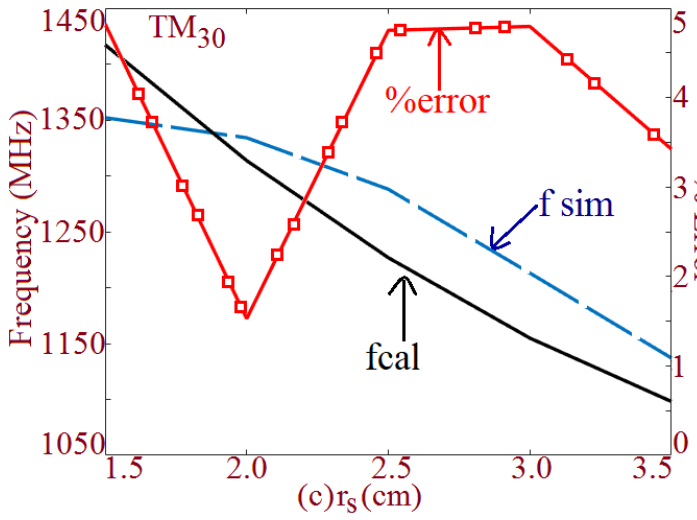

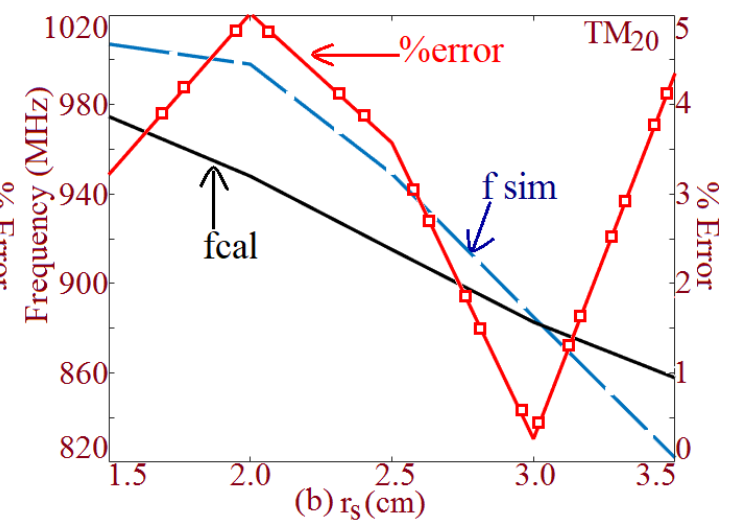

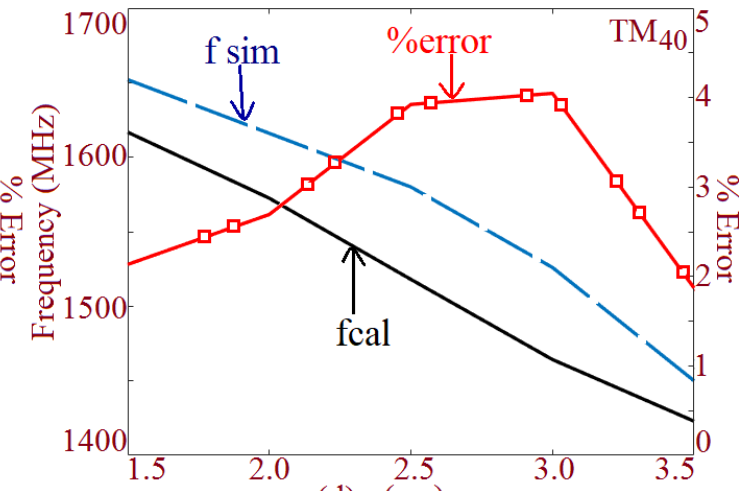

(d) $\mathrm{r}_{\mathrm{S}}(\mathrm{cm})$

Fig. 3 Frequency and \% error plots at (a) $\mathrm{TM}_{10}$, (b) $\mathrm{TM}_{20}$, (c) $\mathrm{TM}_{30}$ and (d) $\mathrm{TM}_{40}$ modes for Crescent shape MSA 


\section{Multi-BAnd DuAl POlarized CRescent Shape MSAS}

As observed from the resonance curves shown in Fig. 1(c), changes in feed location increases input impedance at two modes and reduces at other two modes. Hence for given feed location, impedance matching at all four resonant modes is not obtained for multi-band response. Therefore, with reference to first three resonant modes, Crescent shape MSA is optimized for triple frequency response. For $\mathrm{r}_{\mathrm{s}}=$ 2.7, $\mathrm{x}_{\mathrm{f}}=2.5$ and $\mathrm{y}_{\mathrm{f}}=2.0 \mathrm{~cm}$, optimized return loss $\left(\mathrm{S}_{11}\right)$ plot is shown in Fig. 4(a). Simulated frequencies and their respective BW's are 576, 918 and $1250 \mathrm{MHz}$ and 7, 18 and $17 \mathrm{MHz}$. Measured frequencies and their respective BW's are 580, 918 and $1245 \mathrm{MHz}$ and 8,16 and $21 \mathrm{MHz}$. The fabricated prototype is shown in Fig. 4(b). The pattern was measured at three frequencies. At each frequency it is in the broadside direction. At second resonant mode $\left(\mathrm{TM}_{20}\right) \mathrm{E}$ and $\mathrm{H}$-planes are aligned along $\Phi=0^{\circ}$ and $90^{\circ}$, respectively. At first $\left(\mathrm{TM}_{10}\right)$ and third $\left(\mathrm{TM}_{30}\right)$ resonant mode, $\mathrm{E}$ and H-plane is aligned along $\Phi=90^{\circ}$ and $0^{\circ}$, respectively. Thus Crescent shape MSA offers triple band dual polarized response with similar pattern characteristics.

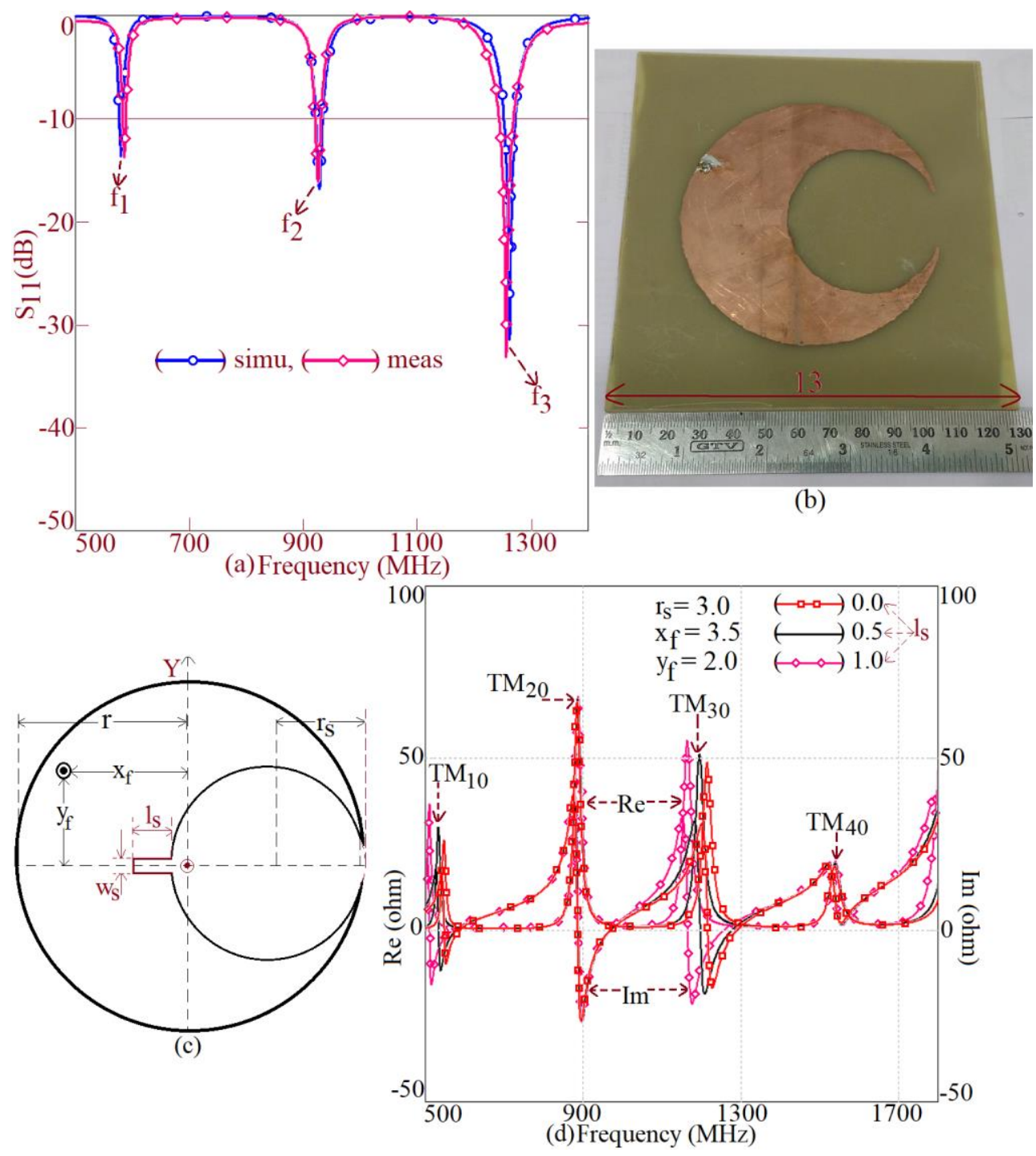

Fig. 4 (a) Return loss plots and (b) fabricated prototype for triple band Crescent shape MSA, (c) slot cut Crescent shape MSA and its (d) resonance curve plots for increasing slot length 
As seen from the resonance curve plots shown in Fig. 1(c), with increase in x-coordinate of the feed location, $\mathrm{TM}_{40}$ mode appears in resonance curve but impedance at $\mathrm{TM}_{10}$ and $\mathrm{TM}_{30}$ mode reduces. Thus, to achieve four band frequency response impedance at first and third modes needs to be controlled so as to realize VSWR less than 2 at all the four frequencies. The impedance at $\mathrm{TM}_{10}$ and $\mathrm{TM}_{30}$ modes is increased by cutting a slot which is orthogonal to their modal surface currents as shown in Fig. 4(c). The slot being orthogonal to these currents reduces $\mathrm{TM}_{10}$ and $\mathrm{TM}_{30}$ mode frequencies and also increases the impedance at them as shown in Fig. 4(d). Slot is parallel to surface currents at $\mathrm{TM}_{20}$ and $\mathrm{TM}_{40}$ modes, hence their frequencies and impedance remains unchanged. Thus, rectangular slot realizes tuning of impedance and frequencies of first four resonant modes of Crescent shape MSA to realize four band frequency response. For $\mathrm{r}_{\mathrm{s}}=2.7, \mathrm{1}_{\mathrm{s}}=1.8, \mathrm{x}_{\mathrm{f}}=3.8$ and $\mathrm{y}_{\mathrm{f}}=1.9 \mathrm{~cm}$, optimum response is shown in Fig. 5(a). In four band MSA, simulated frequencies and their respective BW's are 486, 922, 1154 and $1562 \mathrm{MHz}$ and 6, 16, 17 and $19 \mathrm{MHz}$. The antenna was fabricated and the experiment was carried out. The measured frequencies and respective BW's are 470, 895, 1123 and $1530 \mathrm{MHz}$ and 7, 16, 18 and $19 \mathrm{MHz}$. The fabricated prototype of the antenna is shown in Fig. 5(b). The radiation pattern at four frequencies is shown in Fig. 5(c, d) and 6(a-f).
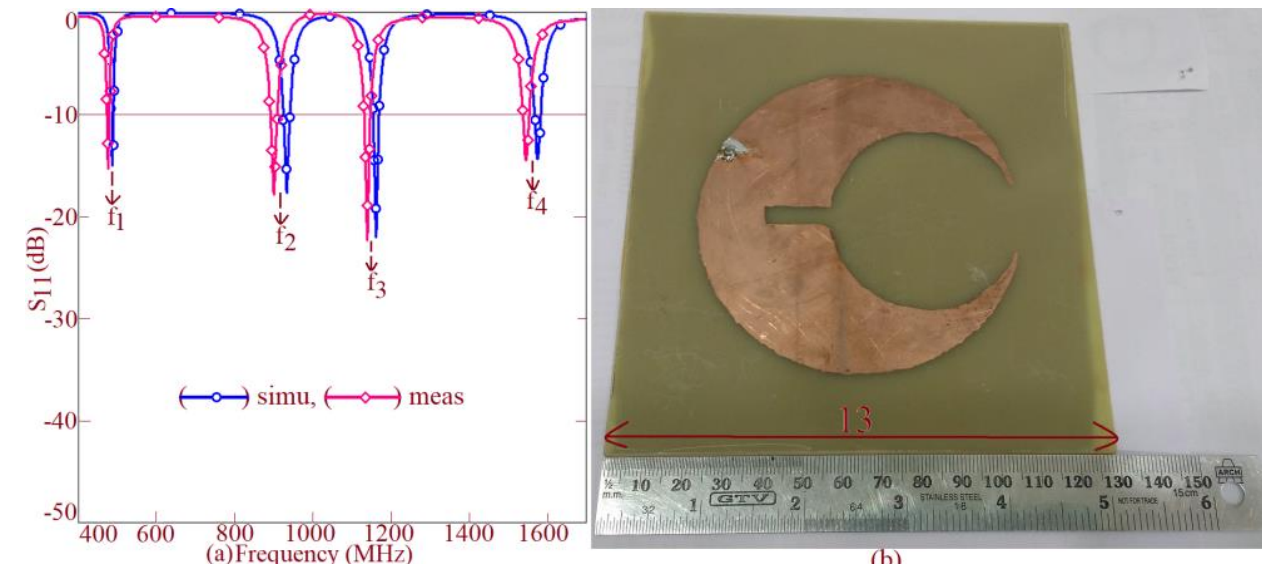

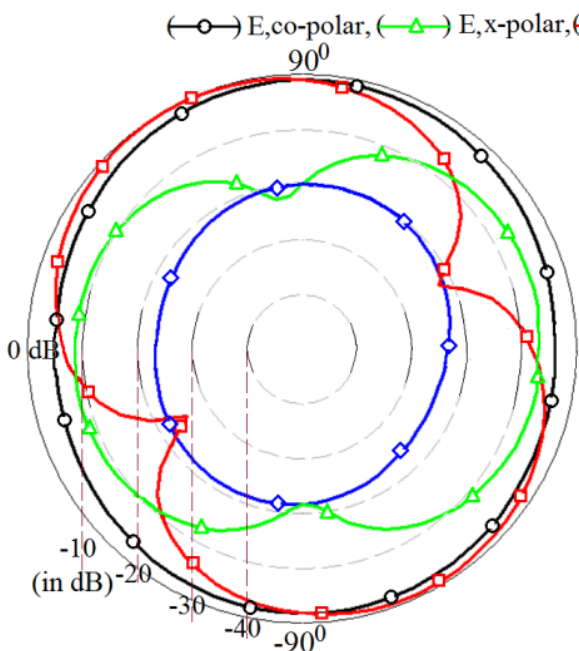

(c) $\mathrm{f}=486 \mathrm{MHz}$, simulated

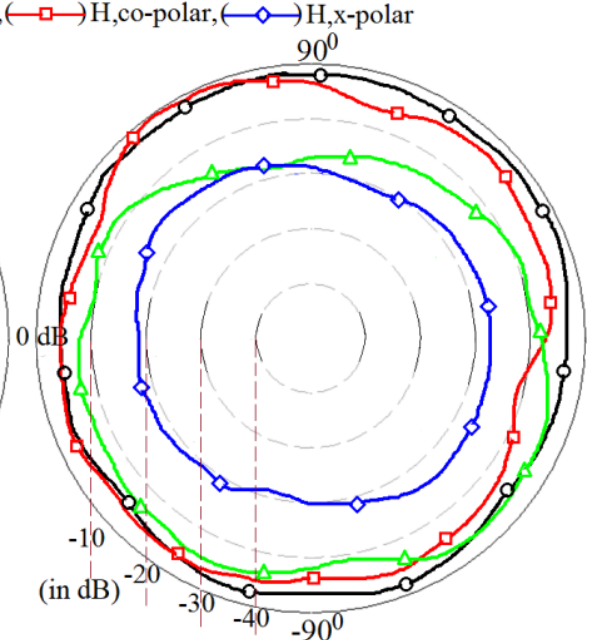

(d) $\mathrm{f}=470 \mathrm{MHz}$, measured

Fig. 5 (a) Return loss plots and (b) fabricated prototype for slot cut Crescent shape MSA, and its (c, d) radiation pattern at first frequency (fTM10) 


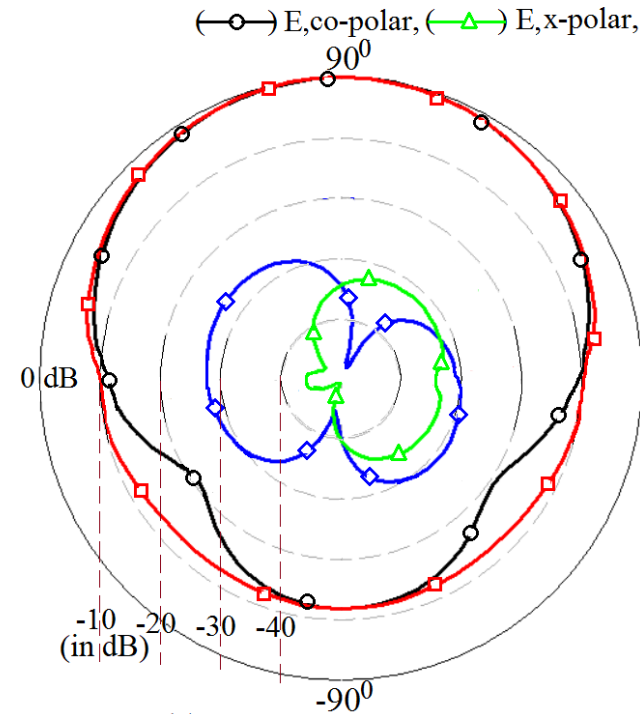

(a) $\mathrm{f}=922 \mathrm{MHz}$, simulated

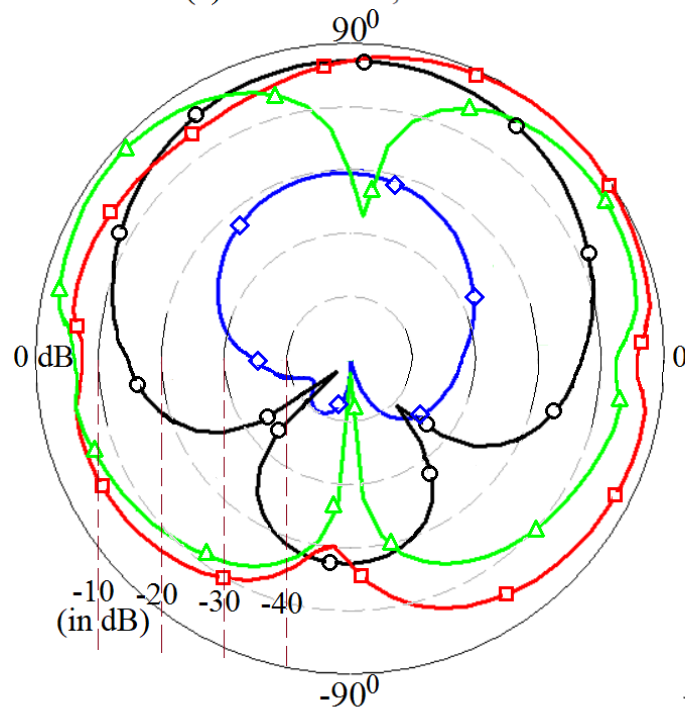

(c) $\mathrm{f}=1154 \mathrm{MHz}$, simulated

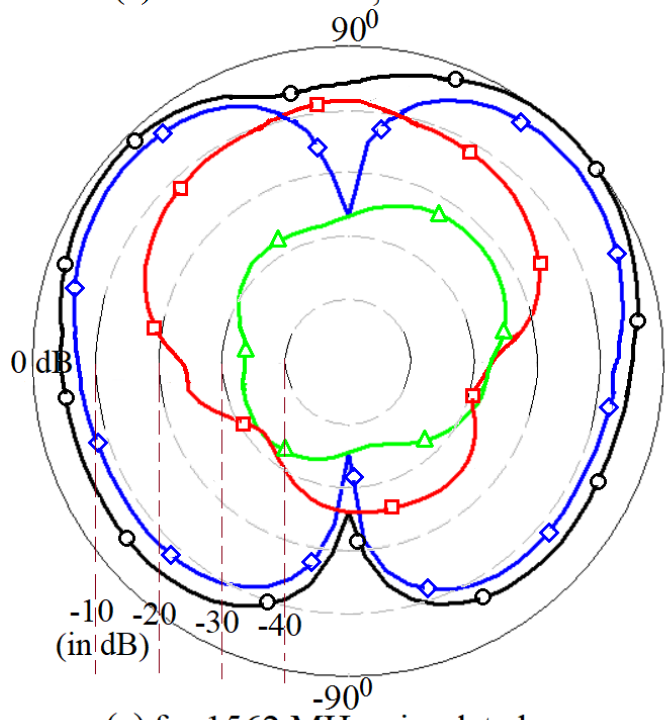

(e) $\mathrm{f}=1562 \mathrm{MHz}$, simulated

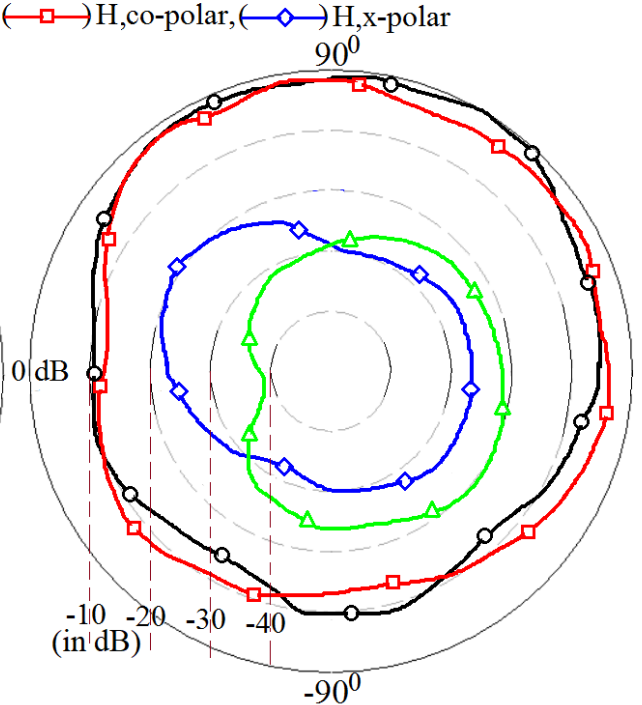

(b) $\mathrm{f}=895 \mathrm{MHz}$, measured

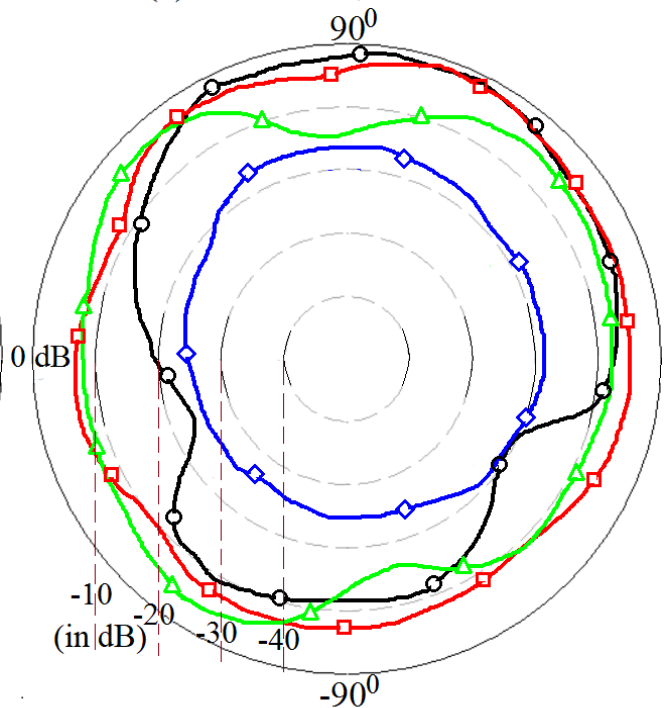

(d) $\mathrm{f}=1123 \mathrm{MHz}$, measured

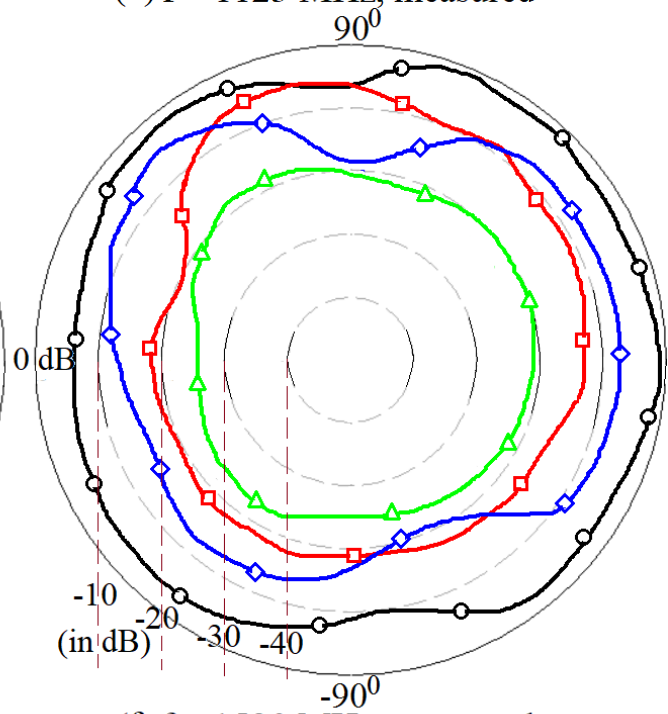

(f) $\mathrm{f}=1530 \mathrm{MHz}$, measured

Fig. 6 Radiation pattern at (a, b) second (fтM20) (c, d) third frequency (fтM30) and (e, f) fourth frequency (f f $_{\text {TM40 }}$ ) for slot cut Crescent shape MSA 
The pattern at all the frequencies shows radiation in the broadside direction. The E-plane is directed along $\Phi=90^{\circ}$ at first and third frequency whereas at second and fourth frequency, E-plane is directed along $\Phi=0^{0}$. Since MSA is optimized on finite square ground plane of side length $13 \mathrm{~cm}$, larger back-lobe radiation is observed. The finite ground plane is chosen here as in the practical systems larger size of the ground plane will not be available. Thus, proposed design yields broadside dual polarized multi-band frequency response at consecutive resonant modes.

\section{Design OF MUlti-BAND CRESCENT SHAPE MSA}

Using proposed resonant length formulations at each mode, procedure to design multi-band slot cut Crescent shape MSA is discussed here. First resonant length formulation at modified patch modes that accounts for the effects of rectangular slot to give four band dual polarized response is presented. The slot length ' $l_{\mathrm{s}}$ ' only reduces the resonance frequencies of $\mathrm{TM}_{10}$ and $\mathrm{TM}_{30}$ modes as surface currents at them are orthogonal to the slot length. At $\mathrm{TM}_{20}$ (equivalent $\mathrm{TM}_{11}$ ) and $\mathrm{TM}_{40}$ (equivalent $\mathrm{TM}_{21}$ ) modes, minor perturbations in length of the surface currents is observed which is due to slot width ' $\mathrm{w}_{\mathrm{s}}$ '. Thus, resonant length formulations at each mode is realized by using following equations. While formulating every equation, variation in modal frequency and surface currents have been studied to arrive at final expression.

At $\mathrm{TM}_{10}$ mode,

$$
1_{\mathrm{e} 10}=2 \mathrm{r}_{\mathrm{s}} \pi+\left(1_{\mathrm{s}}\left(\mathrm{r} / \mathrm{r}-1_{\mathrm{S}}\right)\right)
$$

$\mathrm{TM}_{20}$ mode,

$$
\mathrm{r}_{\mathrm{e}}=\mathrm{r}+(\mathrm{r} / \mathrm{r})\left(\mathrm{r}_{\mathrm{s}} \pi / 2.9\right)+{ }^{\mathrm{w}} \mathrm{s} / 8
$$

$\mathrm{TM}_{30}$ mode,

$$
1_{\mathrm{e}}=\left(2 \mathrm{r} \pi+2 \mathrm{r}_{\mathrm{s}} \pi\right) / 2.4+\left(1_{\mathrm{s}}\left(\mathrm{r} / 2.5\left(\mathrm{r}-\mathrm{l}_{\mathrm{s}}\right)\right)\right)
$$

$\mathrm{TM}_{40}$ mode,

$$
r_{e}=r+\left(r_{s} / r\right)\left(r_{s} \pi / 2.9\right)+{ }^{w} s / 8
$$

Using (4) resonance frequency of $\mathrm{TM}_{10}$ mode is calculated whereas (6) gives frequency of $\mathrm{TM}_{20}$ (equivalent $\mathrm{TM}_{11}$ ) mode with $\mathrm{k}_{\mathrm{mn}}=1.84118$ and frequency of $\mathrm{TM}_{40}$ (equivalent $\mathrm{TM}_{21}$ ) for $\mathrm{k}_{\mathrm{mn}}=$ 3.05424. Frequency of $\mathrm{TM}_{30}$ mode is calculated by using (8) and (9). At all the resonant modes, frequencies calculated using proposed formulations agrees closely with the simulated frequencies against slot length variation. Using these formulations, procedure to design multi-band Crescent shape MSA is explained. In Crescent shape MSA, slot radius ' $r_{s}$ ' decides the fundamental mode $\left(\mathrm{TM}_{10}\right)$ frequency for the given circular patch radius. As discussed in the formulation above, with increase in 
slot radius, effective patch width reduces that decreases effective dielectric constant. Thus, for designing Crescent shape MSA at given fundamental mode frequency, more than two unknowns are present, they are ' $\varepsilon_{\mathrm{re}}$ ', ' $r$ ' and ' $r_{\mathrm{s}}$ '. The knowledge of variation in ' $\varepsilon_{\mathrm{re}}$ ' against ' $\mathrm{r}_{\mathrm{s}}$ ' is essential. Hence while designing Crescent shape patch, plot of variation in ' $\varepsilon_{\mathrm{re}}$ ' against ' $\mathrm{r}_{\mathrm{s}} / \mathrm{r}$ ' is used for the given substrate. The radius ratio is selected since this fractional number governs $\mathrm{TM}_{10}$ mode frequency as well as effective patch width. For the FR4 substrate, this plot is shown in Fig. 7(a). This plot is generated with reference to Crescent shape MSA discussed above in triple band configuration. For designing Crescent shape MSA for given $\mathrm{TM}_{10}$ frequency, radius ratio is selected first. The design is presented for $\mathrm{f}_{\mathrm{TM} 10}=1000 \mathrm{MHz}$. The ratio ' $\mathrm{r}_{\mathrm{s}} / \mathrm{r}$ ' is selected to be 0.6 for which ' $\varepsilon_{\mathrm{re}}$ ' is found to be 2.4. Using (3) and (4), for $\mathrm{f}_{\mathrm{TM} 10}=1000 \mathrm{MHz}$ frequency on FR4 substrate, ' $\mathrm{r}_{\mathrm{s}}$ ' is calculated to be $1.55 \mathrm{~cm}$ that gives ' $r$ ' as $2.55 \mathrm{~cm}$. For these radius, calculated $\mathrm{TM}_{20}, \mathrm{TM}_{30}$ and $\mathrm{TM}_{40}$ mode frequencies using (4), (6) and (9) are, 1590, 2136 and $2637 \mathrm{MHz}$, respectively. When simulated this Crescent shape MSA shows $\mathrm{TM}_{10}, \mathrm{TM}_{20}, \mathrm{TM}_{30}$ and $\mathrm{TM}_{40}$ mode frequencies as, 1008, 1604, 2187 and $2750 \mathrm{MHz}$, respectively, which are close to their calculated values. The triple band response with reference to first three resonant modes is obtained in Crescent shape patch for ' $\mathrm{xf}_{\mathrm{f}}$ ' $=0.556 \mathrm{r}$ and ' $\mathrm{yf}_{\mathrm{f}}$ ' $=0.444 \mathrm{r}$. For realizing four band response, slot length ' $l_{\mathrm{s}}$ ' is introduced on the edge of Crescent shape MSA. For the given slot radius optimum four band response is obtained for dual frequency ratio $\left(\mathrm{TM}_{20} / \mathrm{TM}_{10}\right)$ of 1.845. Using formulations given in (10) - (13), various modal frequencies against slot length variations are obtained and ratio plot for first two frequencies is shown in Fig. 7(b). The value of slot length that gives ratio of around 1.845 is noted and it is found to be $1.0 \mathrm{~cm}$. The feed point parameters for four band response are taken in the range of $x_{f}=(0.75-0.84) r$ and $y_{f}=(0.38-0.42) r$. The Crescent shape MSA is simulated for these antenna dimensions. The simulated values of the resonant mode frequencies as observed from the resonance curve plot are, 871, 1604, 2037 and $2750 \mathrm{MHz}$. The calculated values using proposed formulation are, 852, 1567, 2048 and $2625 \mathrm{MHz}$, which are close to simulated results with less than $5 \%$ error. The simulated and measured return loss plots are shown in Fig. 7(c). The simulated values of center frequencies of each band and their BW are, 875, 1613, 2042, 2763 and 13, 26, 32, $53 \mathrm{MHz}$, respectively. Measured values of frequency and BW are, 860, 1590, 2022, 2748 and 14, 25, 30, $50 \mathrm{MHz}$, respectively. The center frequency of BW in $\mathrm{S}_{11}$ plot differs from the frequencies observed in their resonance curve due to the probe inductance. Thus, proposed formulations can be used to design multi-band Crescent shape MSA for given slot radius. Similarly design of Crescent shape MSA can be implemented using proposed formulations for different radius ratio as well as at different fundamental mode frequency. 

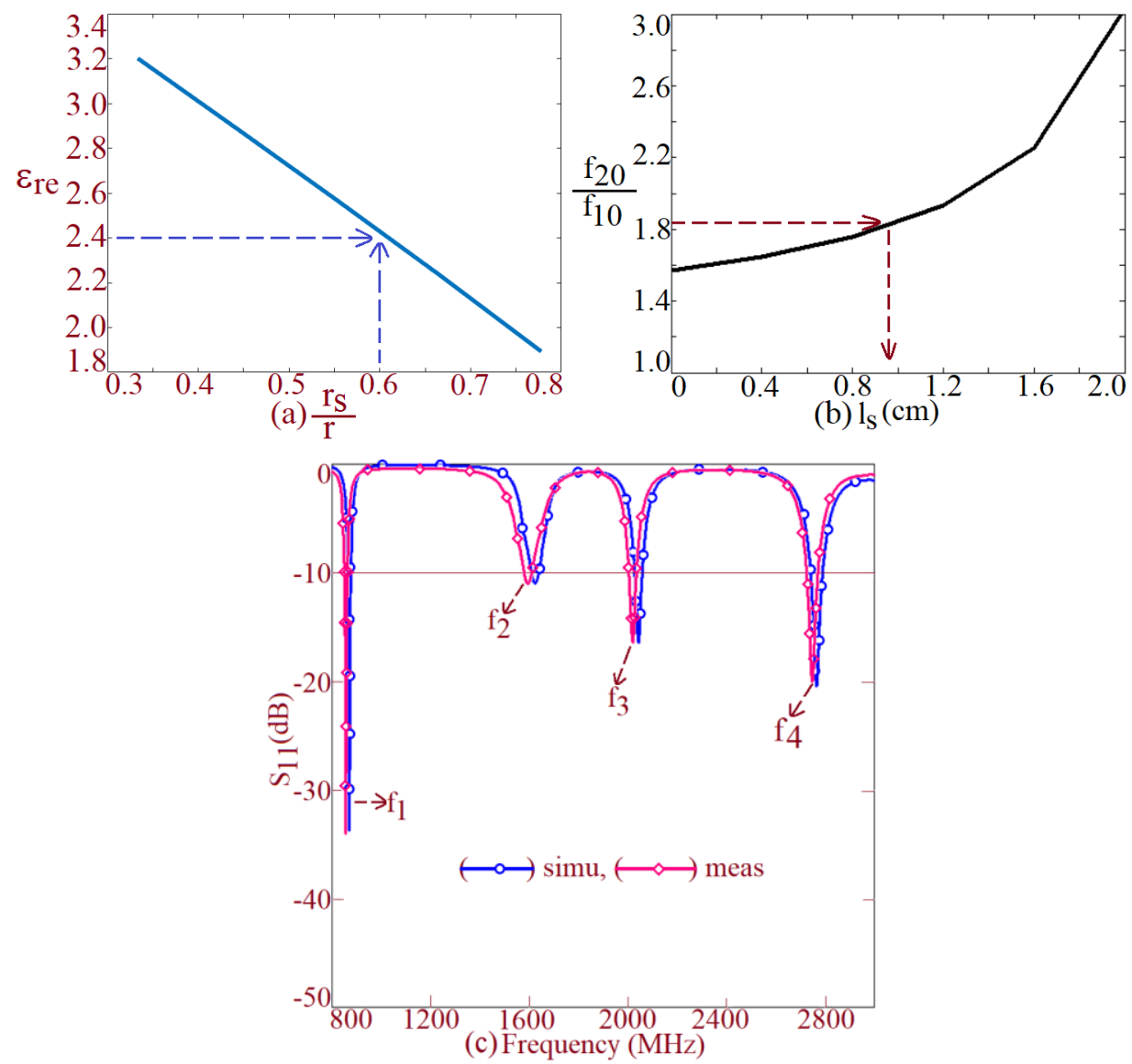

Fig. 7 (a) Plot of variation in Ere against slot radius for Crescent shape MSA, (b) frequency ratio plot against slot length variation and (c) optimum return loss plots for slot cut Crescent shape MSA

\section{AIR SUSPENDED DESIGN OF CRESCENT SHAPE MSA}

The above variations of Crescent shape MSA were studied using glass epoxy substrate, hence they have lower gain. To increase the gain, its suspended variation is designed. Here patch is fabricated on glass epoxy substrate which is suspended above the ground plane using an air gap of $0.16 \mathrm{~cm}$. The effective dielectric constant $\left(\varepsilon_{\text {re }}\right)$ of suspended configuration is calculated by using (14) and patch radius for $\mathrm{TM}_{11}$ mode frequency of around $850 \mathrm{MHz}$ is calculated using (15).

$$
\begin{gathered}
\varepsilon_{\mathrm{re}}={ }^{\left(\mathrm{h}_{1}+\mathrm{h}_{2}\right) \varepsilon_{\mathrm{r} 1} \varepsilon_{\mathrm{r} 2} / \mathrm{h}_{1} \varepsilon_{\mathrm{r} 2}+\mathrm{h}_{2} \varepsilon_{\mathrm{r} 1}} \\
\mathrm{r}=30 \mathrm{k}_{\mathrm{mn}} / 2 \mathrm{f}_{\mathrm{r}} \pi \sqrt{\varepsilon_{\mathrm{re}}}
\end{gathered}
$$

Here, $h_{1}$ and $h_{2}$ are thickness for air and glass epoxy substrate, which equals to $0.16 \mathrm{~cm}$. The $\varepsilon_{\mathrm{r} 1}$ is dielectric constant of air and $\varepsilon_{\mathrm{r} 2}$ is the dielectric constant of glass epoxy substrate. The detailed parametric study for variations in slot radius, horizontal slot length for optimizing four band frequency response was carried out. However, it was noted that with additional rectangular slot as used in Crescent MSA shown in Fig. 3(c), impedance matching at four resonant modes was not realized. In suspended patch, loss tangent of the configuration reduces, which affects the variations in 
Journal of Microwaves, Optoelectronics and Electromagnetic Applications, Vol. 18, No. 1, March 2019 DOI: http://dx.doi.org/10.1590/2179-10742019v18i11333

impedances across various modes over the patch. Therefore, for optimizing the suspended design, pair of inclined rectangular slots were used in Crescent shape MSA, as shown in Fig. 8(a). For the optimum MSA dimensions as shown in Fig. 8(a), return loss plots are shown in Fig. 8(b). Simulated multi-band frequencies and respective BW's are 625, 740, 988 and $1464 \mathrm{MHz}$ and 9, 11, 18 and 15 MHz. The measured frequencies with their respective BW's are 600, 722, 970 and $1448 \mathrm{MHz}$ and 8, 12, 17 and $17 \mathrm{MHz}$. Antenna offers broadside pattern characteristics with co-polar broadside gain of around 1.5 to $6 \mathrm{dBi}$ across multiple frequencies as shown in Fig. 8(c). The variation in gain across different modes is attributed to variation in cross polar components of radiation as well as varying electrical thickness of substrate across multiple resonant modes. The fabricated prototype of the suspended antenna is shown in Fig. 8(d).

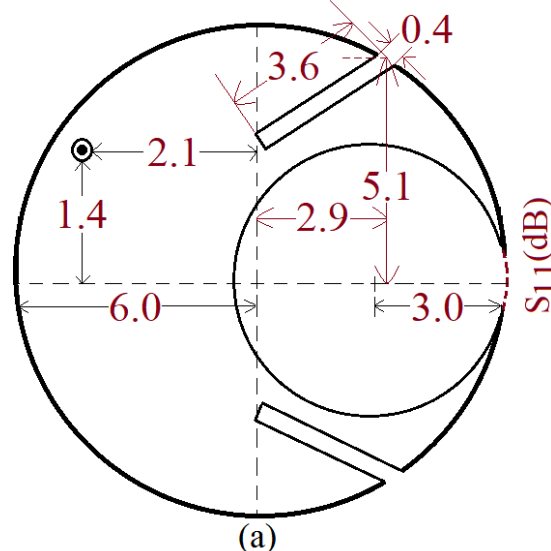

(a)
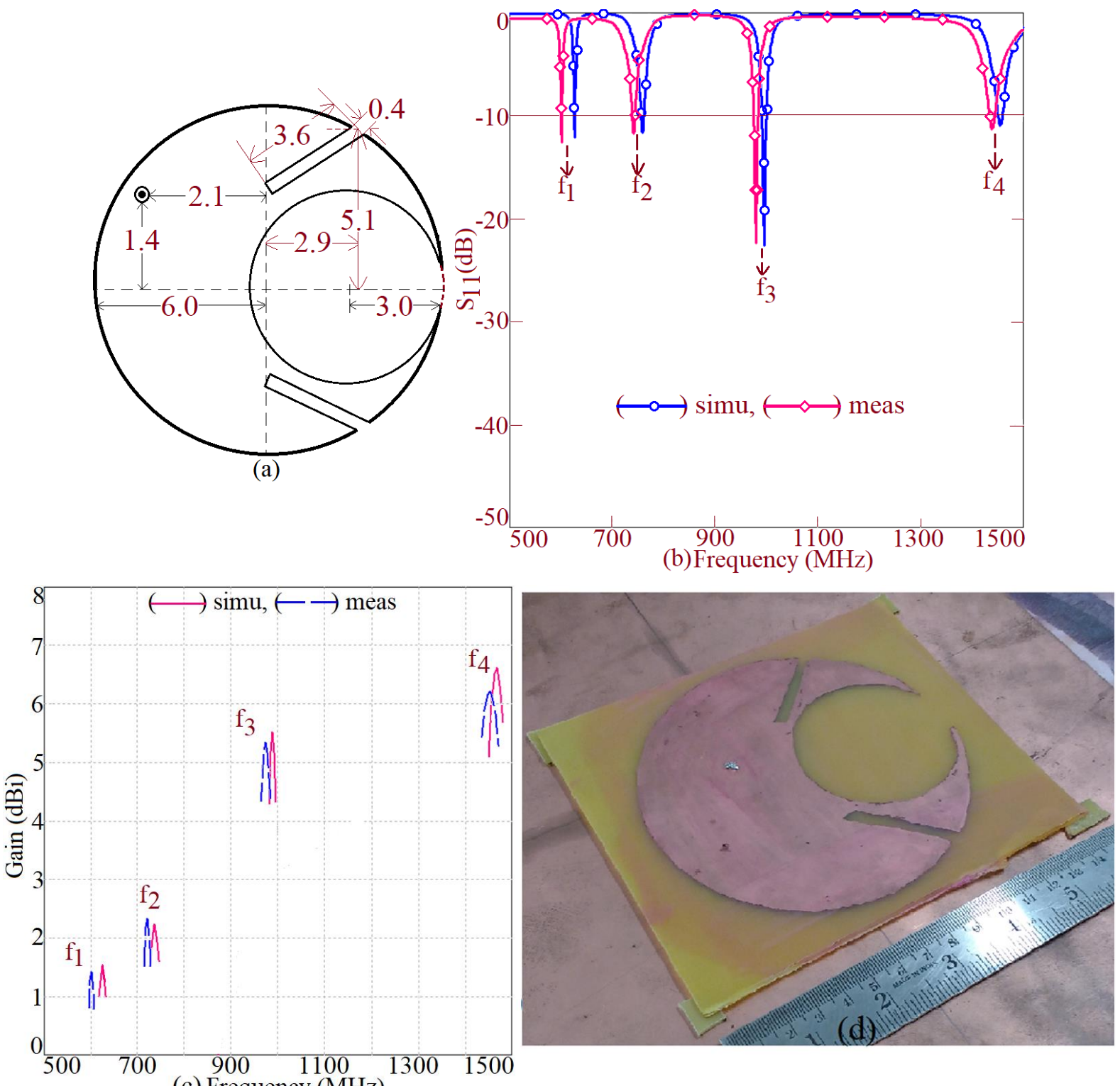

(c) Frequency $(\mathrm{MHz})$

Fig. 8 (a) Air suspended design of slot cut Crescent shape MSA, its (b) return loss plots, its (c) gain variation over multiple frequencies and its (d) fabricated prototype 
Thus, in the proposed work, new design of Crescent shape MSA is presented. By studying the modal current distributions, resonant length formulations at fundamental and higher order modes are proposed. Frequencies obtained using them agrees closely with the simulated result. Using proposed formulations procedure to design multiband Crescent shape patch is also presented. Although Crescent shape patch is reported in the literature however detailed discussion about its resonant modes is missing. The present work provides detailed study for the same. Also, in the literature different configurations to realize multi-band response are reported. However, proposed design offers multiband response with dual polarizations at consecutive resonant modes. With reference to modes present in Crescent shape patch proposed study explains optimization process for triple and four band response. Hence a new configuration of Crescent shape MSA with its resonant length formulations and multi-band designs for dual polarizations are the novelties in the proposed study. With the given multi-band characteristics, proposed multi-band MSA can find applications in indoor and personal communication systems.

\section{CONCLUSIONS}

Novel design of Crescent shape MSA is presented, which offers new resonant modes those lies nearer to the modes of equivalent circular patch. For the new geometry resonant length formulations at fundamental and some of higher order modes are presented. Frequencies calculated using them for varying slot radius offers close match with the simulations. Further triple and four band configurations of Crescent shape MSA are presented. They yield dual polarized response at consecutive resonant modes with 1 to $1.5 \%$ of VSWR BW. To improve the gain characteristics, air suspended design of Crescent shape MSA is proposed, which yields gain of 1.5 to $6 \mathrm{dBi}$ across multiple frequencies.

\section{REFERENCES}

[1] C. A. Balanis, Antenna Theory \& Design, $3^{\text {rd }}$ ed., John Wiley \& Sons Inc. Publication, 2005.

[2] R. Garg, P. Bhartia, I. Bahl, Microstrip Antenna Design Handbook, Artech House, USA, 2001.

[3] G. Kumar and K. P. Ray, Broadband Microstrip Antennas, $1^{\text {st }}$ ed., Artech House, USA, 2003.

[4] K. L. Wong, Compact and Broadband Microstrip Antennas, $1^{\text {st }}$ ed., John Wiley \& sons, Inc., New York, USA, 2002.

[5] M. C. Lim, S. K. A. Rahim, M. R. Hamid, A. A. Eteng and M. F. Jamlos, "Frequency Reconfigurable Antenna for WLAN application,” Microwave \& Optical Technology Letters, vol. 59, no. 1, pp. 171 - 176, 2017.

[6] N. N. Trong, L. Hall and C. Fumeaux, "A Frequency and Polarization reconfigurable stub loaded Microstrip Patch Antenna," IEEE Transactions on Antennas and Propagation, vol. 63, no. 11, pp. 5235 - 5240, 2015.

[7] X. Q. Zhu, Y. X. Guo and W. Wu, "Miniaturized dual band dual polarized Antenna for MBAN applications," IEEE Transactions on Antennas and Propagation, vol. 64, no. 7, pp. 2805 - 2813, 2016.

[8] C. X. Mao, S. Gao, Y. Wang, B. S-Izquierdo, Z. Wang, F. Qin, Q. X. Chu, J. Li, G. Wei and J. Xu, "Dual-band Patch antenna with filtering performance and Harmonic Suppression," IEEE Transactions on Antennas and Propagation, vol. 64, no. 9, pp. 4074 - 4077, 2016.

[9] M. Gulam, N. Alsath, and M. Kanagasabai, "Planar pentaband Antenna for vehicular communication application," IEEE Antennas and Wireless propagation Letters, vol. 13, pp. 110 - 113, 2014. 
Journal of Microwaves, Optoelectronics and Electromagnetic Applications, Vol. 18, No. 1, March 2019 DOI: http://dx.doi.org/10.1590/2179-10742019v18i11333

[10] A. A. Deshmukh, and K. P. Ray, "Stub loaded Multi-band slotted Rectangular Microstrip Antennas," IET Microwave Antennas and Propagation, vol. 3, no. 3, pp. 529 - 535, 2009.

[11] J. Anguera, C. Puente, and C. Borja, "Dual Frequency Broadband Microstrip Antenna with a Reactive Loading and Stacked Elements,” Progress In Electromagnetics Research Letters, vol. 10, pp. 1 - 10, 2009.

[12] J. Anguera, C. Puente, C. Borja, and J. Soler, "Fractal-Shaped Antennas: a Review," in RF and Microwave Engineering, K. Chang, Eds., Wiley Encyclopedia, vol.2, pp.1620-1635, 2005.

[13] J. M. J. W. Jayasinghe, J. Anguera, and D.N. Uduwawala, "A simple design of multi band microstrip patch antennas robust to fabrication tolerances for GSM, UMTS, LTE, and Bluetooth applications by using genetic algorithm optimization,” Progress In Electromagnetics Research M, vol. 27, pp. 255 - 269, 2012.

[14] C. Puente, J. Anguera, and C. Borja, "Dual-band dual-polarized antenna array," US Patent US6937206 B2, 2005.

[15] T. Mandal and S. Das, "Microstrip feed Spanner Shape Monopole Antennas for Ultra Wide Band Applications," Journal of Microwaves, Optoelectronics and Electromagnetic Applications, vol. 12, no. 1, pp. 15 - 22, 2013.

[16] M. U1 Hassan, F. Arshad, S. I. Naqvi, Y. Amin, H. Tenhunen, "A Compact Flexible and Frequency Reconfigurable Antenna for Quintuple Applications," Radioengineering Journal, vol. 26, no. 3, pp. 655 - 661, 2017.

[17] A. T. Abed, M. S. Jit Singh, M. T. Islam, A. D. Khaleel, "Dual crescent-shaped slot antenna fed by circular polarisation into dual orthogonal strip lines," IET Microwave Antennas and Propagation, vol. 11, no. 15, pp. 2129 $-2133,2017$.

[18] M. N. Rahman, M. T. Islam, M. Z. Mahmud, M. Samsuzzaman, "Compact microstrip patch antenna proclaiming super wideband characteristics," Microwave \& Optical Technology Letters, vol. 59, pp. 2563 - 2570, 2017.

[19] N. C. Azenui, H. Y. D. Yang, “A Printed Crescent Patch Antenna for Ultrawideband Applications," IEEE Antennas and Wireless Propagation Letters, vol. 6, pp. 113 - 116, 2007. 